\title{
Effects of different doses of dexmedetomidine on heart rate and blood pressure in intensive care unit patients
}

\author{
XIAOYAN ZHANG, RUILAN WANG, JIAN LU, WEI JIN, YONGBIN QIAN, PEIJIE HUANG, RUI TIAN and YAN LI \\ Department of Emergency, First People's Hospital Affiliated to Shanghai Jiao Tong University, Shanghai 200080, P.R. China
}

Received October 14, 2014; Accepted September 15, 2015

DOI: $10.3892 /$ etm.2015.2872

\begin{abstract}
The aim of the present study was to observe and compare the sedative effect of different doses of DEX on heart rate (HR) and blood pressure (BP) in critically ill patients admitted to intensive care units (ICUs). The study included patients that were retained in ICUs and required sedation between January and March 2014. Patients were excluded if they had a BP of $>200 \mathrm{mmHg}$, a HR of $<60 \mathrm{bpm}$ or were in a state of shock. The included patients were randomized into three groups: Group A, $1.0 \mu \mathrm{g} / \mathrm{kg} / 10$ min DEX; group B, $0.5 \mu \mathrm{g} / \mathrm{kg} / 10 \mathrm{~min} \mathrm{DEX}$; and group C, $0.4 \mu \mathrm{g} / \mathrm{kg} / \mathrm{h}$ DEX. After receiving these initial designated doses of DEX via an intravenous (IV) infusion pump for $10 \mathrm{~min}$, the patients were maintained continuously at an identical dose of $0.4 \mu \mathrm{g} / \mathrm{kg} / \mathrm{h}$ DEX. Ramsay score, HR, systolic blood pressure (SBP), diastolic blood pressure (DBP), breathing rate (BR) and peripheral capillary oxygen saturation $\left(\mathrm{SpO}_{2}\right)$ were recorded prior to the IV pump infusion and at 2, 4, 6, 8, 10, 60, 120, 180 and 240 min following infusion. Patients in groups A and $\mathrm{B}$ achieved sedation more rapidly compared with those in group $\mathrm{C}(\mathrm{P}<0.05)$. HR decreased more significantly at 8 and 60 min after the initial IV pump infusion with DEX in groups $\mathrm{A}$ and $\mathrm{B}$ compared with group $\mathrm{C}(\mathrm{P}<0.05)$. SBP decreased significantly at $10 \mathrm{~min}$ after IV pump infusion in group A compared with groups $\mathrm{B}$ and $\mathrm{C}(\mathrm{P}<0.05)$. No significant difference existed in the SBP reduction trend between the three groups during the maintenance period. Therefore, the routine dose of DEX $(0.4 \mu \mathrm{g} / \mathrm{kg} / \mathrm{h})$ provides an ideal sedative effect in ICU patients. The recommended loading dose for a more rapid sedation is $0.5 \mu \mathrm{g} / \mathrm{kg} / \mathrm{h}$. High loading doses of DEX via IV pump infusion should be avoided in elderly individuals, patients with acute exacerbation of chronic obstructive pulmonary disease and anemic patients, in whom combination medication, such as midazolam or propofol, may be considered when necessary.
\end{abstract}

Correspondence to: Dr Yan Li, Department of Emergency, First People's Hospital Affiliated to Shanghai Jiao Tong University, 650 Xinsongjiang Road, Songjiang, Shanghai 200080, P.R. China E-mail: criticalcare@163.com

Key words: dexmedetomidine, sedation, bradycardia, intensive care

\section{Introduction}

Ideal sedatives for use in intensive care units (ICUs) should have following properties: Rapid action, easy control of the depth of sedation, minor impact on respiratory function, no accumulation of metabolites, no obvious interference with other medicine and multiple in vivo metabolic pathways, eliminating without relying on liver, kidney or pulmonary function, low cost and minimal side effects (1). At present, no medicine exhibits all of the aforementioned conditions, and benzodiazepines, opioid agonist, propofol and $\alpha 2$-epinephrine agonists are commonly used in ICUs. However, it has been demonstrated that high speed injection and high dose of midazolam may result in respiratory depression and reduced blood pressure, particularly in those elderly, hypovolemic patients or patients with respiratory failure (2). Furthermore, high-dose infusion of propofol for an extended period may cause propofol infusion sydrome, which may involve serious lactic acidosis, hyperlipemia, liver fatty infiltration, rhabdomyolysis and mortality (3). Therefore, these is a requirement for alternative sedative agents for use in ICUs

Dexmedetomidine (DEX) is a highly selective $\alpha_{2}$-adrenoceptor agonist with sedative, analgesic, anti-anxiety and sympathetic nerve inhibitory activities. Patients receiving DEX may be awakened easily without producing respiratory arrest. Therefore, DEX has been considered to be an ideal sedative and analgesic agent for use in intensive care unit (ICU) patients $(4,5)$. DEX is the dextro-isomer of medetomidine, which exerts sedative and analgesic effects. In addition, DEX has been shown to exert neuroprotective effects (6) by agitating $\alpha 2$ receptor mediated the receptor tyrosine kinase phosphorylation. Furthermore, DEX promotes the release of various growth factors by agitating astrocytes to participate in neural protection (7). DEX is able to activate survival promoting enzymes by activating $\alpha 2$ adrenoceptor may exertcardioprotective effects by adjusting the protein kinase, protein kinase $\mathrm{B}$ and endothelial nitric oxide synthase pathways extracellularly (8).

Currently, the infusion speed of DEX in mechanical ventilation patients ranges between 0.2 and $0.7 \mu \mathrm{g} / \mathrm{kg} / \mathrm{h}$. Previous studies have shown that DEX is safe for use in healthy patients at 10-15 times the normal dosage, producing no obvious side effects or loss of blood pressure and heart rate (9-11). However, a previous study indicated that DEX may reduce blood pressure and heart rate in critical patients, potentially necessitating drug discontinuation (12). 
It was observed in our clinical practice that certain patients receiving the recommended loading dose $(1.0 \mu \mathrm{g} / \mathrm{kg} / 10 \mathrm{~min})$ plus the maintenance dose $(0.2-0.7 \mu \mathrm{g} / \mathrm{kg} / \mathrm{h})$ of DEX for sedation developed hypotension and bradycardia (13). In specific patients, DEX administration had to be suspended, even in certain serious cases. These observations are consistent with the most commonly known adverse reactions of DEX, which include hypotension, nausea, bradycardia and dry mouth (14). However, critically ill patients in ICUs are physiopathologically different from patients undergoing selective surgery, since they frequently exhibit multi-organ dysfunctions involving the heart, liver and kidney (15); therefore, the in vivo metabolic process of DEX in ICU patients may also be different.

The aim of the present study was to determine the optimal dose of DEX for use in ICU patients by observing and comparing the sedative effect of different doses of DEX on the circulatory system of critically ill patients, in an attempt to provide experimental references for the safe and effective clinical use of DEX.

\section{Materials and methods}

General patient data. This study initially considered a total of 82 patients who were retained in the ICU at the First People's Hospital Affiliated to Shanghai Jiao Tong University (Shanghai, China) and required sedation between January and March 2014. Patients were excluded if they presented blood pressure (BP) of $>200 \mathrm{mmHg}$ and heart rate (HR) of $<60 \mathrm{bpm}$, or if they exhibited circulatory shock. A total of 24 patients were excluded for these reasons. The remaining 58 patients were randomized into three groups: Group A, high-dose group $(1.0 \mu \mathrm{g} / \mathrm{kg} / 10 \mathrm{~min}$ DEX; $\mathrm{n}=18)$; group B, mid-dose group $(0.5 \mu \mathrm{g} / \mathrm{kg} / 10 \mathrm{~min} \mathrm{DEX}$; $\mathrm{n}=24)$; and group C, routine-dose control group $(0.4 \mu \mathrm{g} / \mathrm{kg} / \mathrm{h}$ DEX; $n=16)$. The patients in the three groups initially received the designated doses of DEX via an intravenous (IV) infusion pump for $10 \mathrm{~min}$, and were subsequently maintained continuously at the same dose of $0.4 \mu \mathrm{g} / \mathrm{kg} / \mathrm{h} \mathrm{DEX} \mathrm{(Fig.} \mathrm{1).}$

The study complied with the Declaration of Helsinki. The data collection protocol was approved by the Shanghai First People's Hospital Institutional Review Board. All participants signed informed consent statements that allowed access to their medical records.

Drug administration. DEX (2 ml; Sichuan Guorui Pharmaceutical Co., Ltd., Sichuan, China) was first diluted with $0.9 \%$ sodium chloride solution to a total volume of $4 \mathrm{ml}$. Patients in the three groups received the designated doses of DEX via an IV infusion pump for $10 \mathrm{~min}$, and were then administered continuously with the same dose of $0.4 \mu \mathrm{g} / \mathrm{kg} / \mathrm{h}$ DEX in order to maintain an ideal state of sedation, if no significant adverse reaction occurred. DEX IV infusion was controlled at a rate of 0.2-1.4 $\mu \mathrm{g} / \mathrm{kg} / \mathrm{h}$. Propofol (Fresenius Kabi Deutschland GmbH, Langenhagen, Germany) or midazolam (Jiangsu Enhua Herun Medicine Co., Ltd., Xuzhou, China) was added to achieve appropriate depth of sedation if necessary. If adequate sedation was not achieved using DEX, fentanyl (Yichang Renfu Pharmaceutical Co., Ltd., Yichang, China) was administered in a single dose of 1-4 $\mu \mathrm{g} / \mathrm{kg}$. IV pump infusion was suspended in patients with an $\mathrm{HR}$ of $<50 \mathrm{bpm}$ or $\mathrm{HR}$ that had reduced by $>30 \%$, and a systolic blood pressure (SBP) of $<90 \mathrm{mmHg}$.
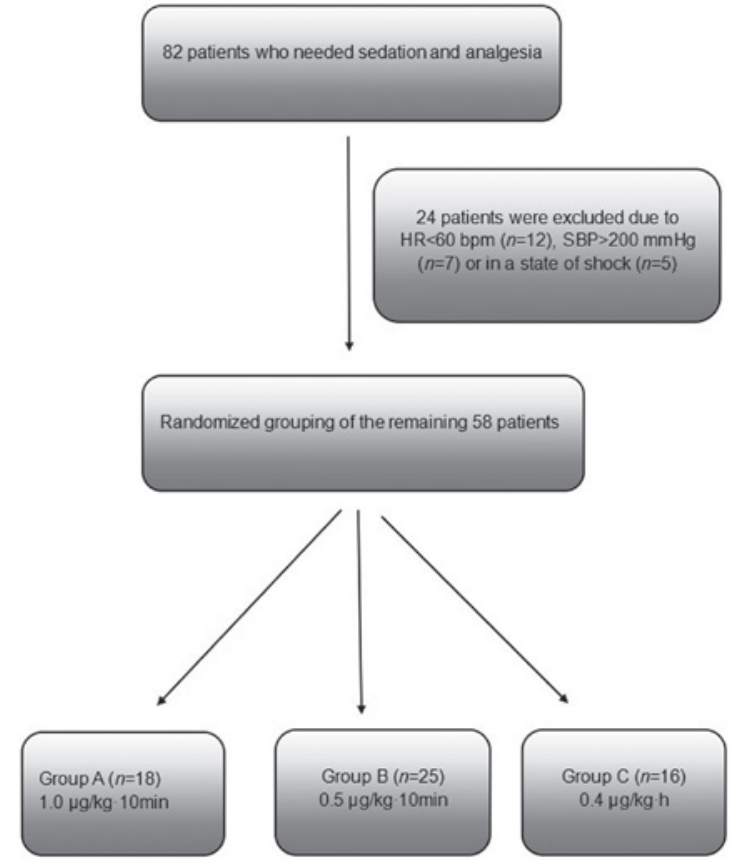

Figure 1. Randomization of the patients into three groups.

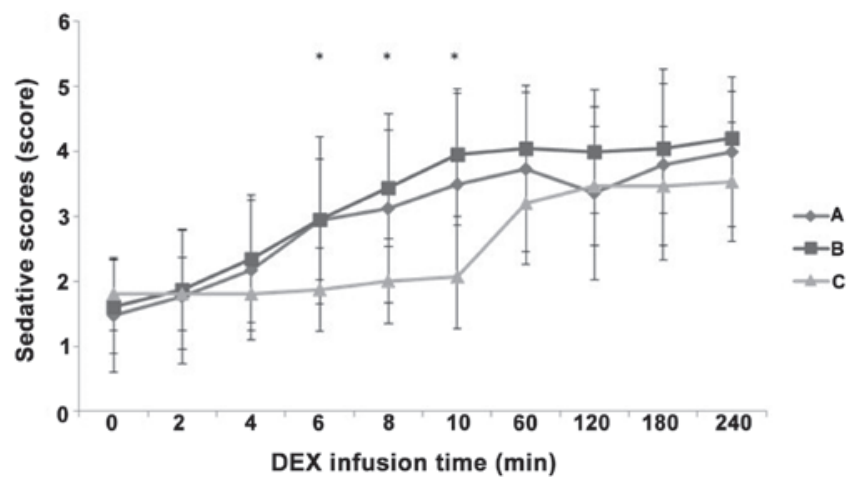

Figure 2. Comparison of sedative scores between the three groups. Group A $1.0 \mu \mathrm{g} / \mathrm{kg} / 10 \mathrm{~min}$; group B, $0.5 \mu \mathrm{g} / \mathrm{kg} / 10 \mathrm{~min}$; and group C, $0.4 \mu \mathrm{g} / \mathrm{kg} / \mathrm{h}$.

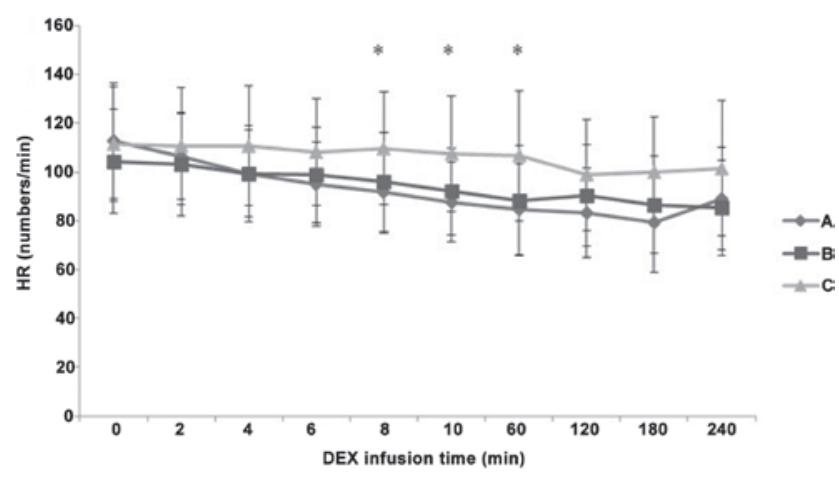

Figure 3. Comparison of HR between the three groups. Group A $1.0 \mu \mathrm{g} / \mathrm{kg} / 10 \mathrm{~min}$; group B, $0.5 \mu \mathrm{g} / \mathrm{kg} / 10 \mathrm{~min}$; and group C, $0.4 \mu \mathrm{g} / \mathrm{kg} / \mathrm{h}$. ${ }^{*} \mathrm{P}<0.05$ vs. group C. HR, heart rate.

Observation parameters. Ramsay score, HR, SBP, diastolic blood pressure (DBP), breathing rate (BR) and peripheral capillary oxygen saturation $\left(\mathrm{SpO}_{2}\right)$ were recorded prior to the IV pump infusion ( $0 \mathrm{~min}$ ) and at 2, 4, 6, 8, 10, 60, 120, 
Table I. General data comparison between the three groups.

\begin{tabular}{|c|c|c|c|}
\hline Parameter & Group A (n=18) & Group B $(n=24)$ & Group C $(n=16)$ \\
\hline Gender (male/female) & $6 / 12$ & $19 / 5$ & $11 / 5$ \\
\hline Age (years) ${ }^{\mathrm{a}}$ & $57.72 \pm 16.50$ & $50.83 \pm 20.53$ & $50.25 \pm 21.43$ \\
\hline APACHE II score ${ }^{\mathrm{a}}$ & $12.78 \pm 5.31$ & $8.54 \pm 4.84$ & $10.44 \pm 7.07$ \\
\hline \multicolumn{4}{|l|}{ Primary diagnosis (n) } \\
\hline AECOPD & 2 & 2 & 1 \\
\hline Severe pneumonia & 1 & 0 & 1 \\
\hline Pneumothorax & 0 & 1 & 0 \\
\hline Cholecystitis & 2 & 1 & 0 \\
\hline Pancreatitis & 0 & 1 & 0 \\
\hline Digestive tract perforation & 1 & 0 & 1 \\
\hline Cirrhosis & 0 & 1 & 0 \\
\hline Upper digestive tract hemorrhage & 0 & 2 & 0 \\
\hline Intestinal obstruction & 1 & 0 & 1 \\
\hline Sepsis & 1 & 1 & 0 \\
\hline Multiple trauma & 3 & 7 & 8 \\
\hline Post-operation & 3 & 4 & 2 \\
\hline Encephalitis & 0 & 2 & 0 \\
\hline Cerebral infarction & 1 & 1 & 2 \\
\hline Poisoning & 1 & 0 & 0 \\
\hline HELLP syndrome & 0 & 1 & 0 \\
\hline Post CPR & 1 & 0 & 0 \\
\hline Multiple myeloma & 1 & 0 & 0 \\
\hline \multicolumn{4}{|l|}{ Organ dysfunction (n) } \\
\hline Respiratory failure & 1 & 2 & 3 \\
\hline Cardiac dysfunction & 2 & 0 & 0 \\
\hline Renal failure & 0 & 0 & 1 \\
\hline \multicolumn{4}{|l|}{ Concomitant use of sedatives (n) } \\
\hline Midazolam & 1 & 1 & 0 \\
\hline Propofol & 0 & 5 & 0 \\
\hline Midazolam + propofol & 0 & 0 & 3 \\
\hline \multicolumn{4}{|c|}{ Concomitant use of vasoactive agents (n) } \\
\hline Norepinephrine & 1 & 1 & 0 \\
\hline Dopamine & 1 & 1 & 1 \\
\hline Norepinephrine + dopamine & 2 & 0 & 0 \\
\hline Use of mechanical ventilation (n) & 11 & 8 & 8 \\
\hline Drug discontinuation (n) & 4 & 4 & 0 \\
\hline
\end{tabular}

${ }^{a}$ Data presented as mean \pm standard deviation. APACHE II, Acute Physiology and Chronic Health Evaluation II; AECOPD, acute exacerbation of chronic obstructive pulmonary disease; HELLP, hemolysis, elevated liver enzymes, low platelet count; CPR, cardiopulmonary resuscitation.

180 and 240 min following infusion. Blood routine, electrolyte, liver/kidney function and blood gas measurements were obtained prior to IV pump infusion. Ramsay Score was evaluated by a physician according to the Ramsay rating scale. HR and SBP were determined using an MP50 electrocardiogram monitor (Philips Healthcare, DA Best, The Netherlands). Blood routine, electrolyte, liver/kidney function, blood gas measurements were obtained using a Beckman Power Processor Sample-Handling System (Beckman Coulter, Inc., Brea, CA, USA). Acute Physiology and Chronic Health Evaluation II (APACHE II) score was calculated (16).

Statistical treatment. Data analysis was performed using SPSS software, version 16.0 (SPSS, Inc., Chicago, IL, USA). The results are expressed as the mean \pm standard deviation. The Shapiro-Wilk test was used in combination with a histogram to determine whether data were normally distributed. Data of normal distribution were analyzed by analysis of variance, and data of non-normal distribution were compared for inter-group 


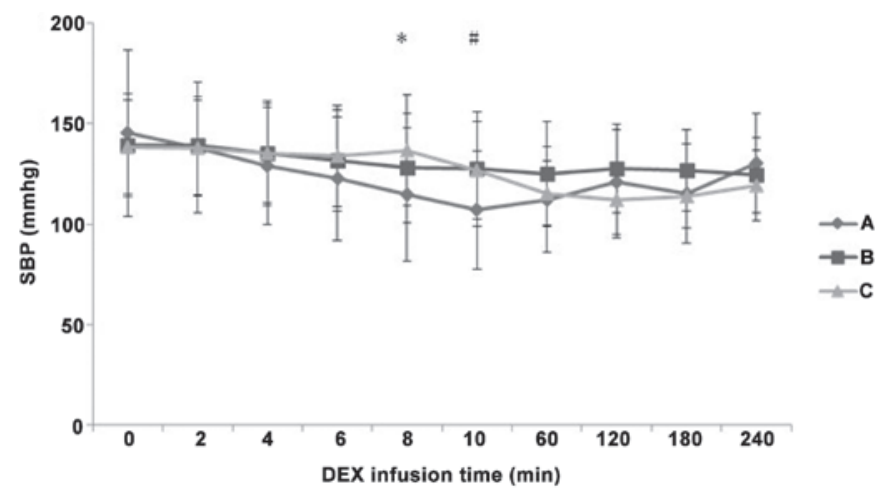

Figure 4. SBP values in the three groups at various time-points after IV pump infusion of DEX. ${ }^{*} \mathrm{C}$ comparison between group $\mathrm{A}$ and $\mathrm{C}, \mathrm{P}<0.05$. ${ }^{*} \mathrm{BC}$ comparison between group A and group $\mathrm{BC}, \mathrm{P}<0.05$. Group $\mathrm{A}, 1.0 \mu \mathrm{g} / \mathrm{kg} / 10 \mathrm{~min}$ DEX; group B, $0.5 \mu \mathrm{g} / \mathrm{kg} / 10 \mathrm{~min}$ DEX; and group C, $0.4 \mu \mathrm{g} / \mathrm{kg} / \mathrm{h}$ DEX; SBP, systolic blood pressure; DEX, dexmedetomidine.

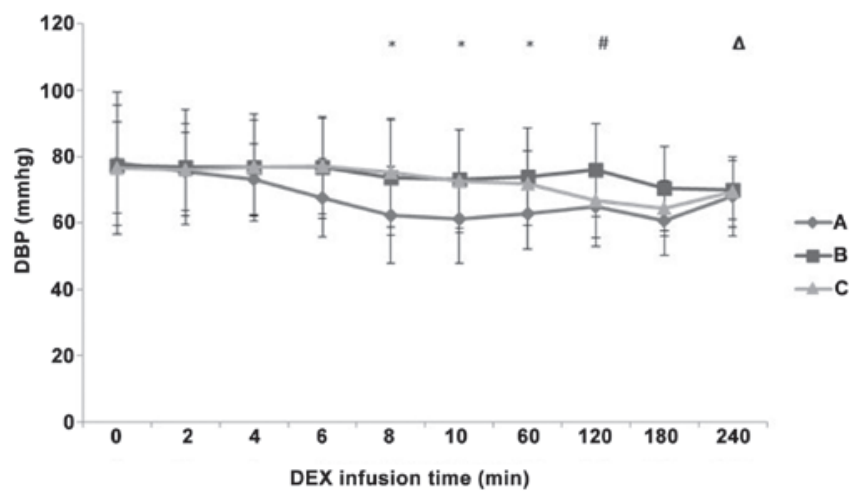

Figure 5. DBP values in the three groups at various time-points after IV pump infusion of DEX. "BC comparison between group A and group $\mathrm{BC}, \mathrm{P}<0.05$. ${ }^{*} \mathrm{AC}$ comparison between group $\mathrm{B}$ and group $\mathrm{AC}, \mathrm{P}<0.05$. "B comparison between group A and B, P $<0.05$. Group A, $1.0 \mu \mathrm{g} / \mathrm{kg} / 10 \mathrm{~min}$ DEX; group B, $0.5 \mu \mathrm{g} / \mathrm{kg} / 10 \mathrm{~min}$ DEX; and group C, $0.4 \mu \mathrm{g} / \mathrm{kg} / \mathrm{h}$ DEX; DBP, diastolic blood pressure; DEX, dexmedetomidine.

difference using the Mann-Whitney $\mathrm{U}$ nonparametric test. Categorical data were tested using the $\chi^{2}$ test. $\mathrm{P}<0.05$ was considered to indicate a statistically significant difference.

\section{Results}

General data comparison. General patient characteristics in the three groups are listed in Table I. No statistically significant difference was observed in the APACHE II score, gender, age and primary diagnosis between the three groups $(\mathrm{P}>0.05)$.

Achievement of the sedative state. Patients in all three groups achieved an ideal state of sedation at $1 \mathrm{~h}$ after IV pump infusion of DEX, with a Ramsay score of 3-4 (P>0.05). Groups A and $\mathrm{B}$ achieved an ideal state of sedation at $6 \mathrm{~min}$, which was more rapid compared with group $\mathrm{C}(\mathrm{P}<0.05$; Fig. 2$)$.

Differences in HR, SBP and DBP following IV pump infusion of $D E X$. A decreasing tendency was observed in the HR, SBP and DBP values following the initial IV pump infusion of DEX in all three groups (Figs. 3-5). HR decreased more notably in groups $\mathrm{A}$ and $\mathrm{B}$ compared with group $\mathrm{C}$ at $8 \mathrm{~min}$ and

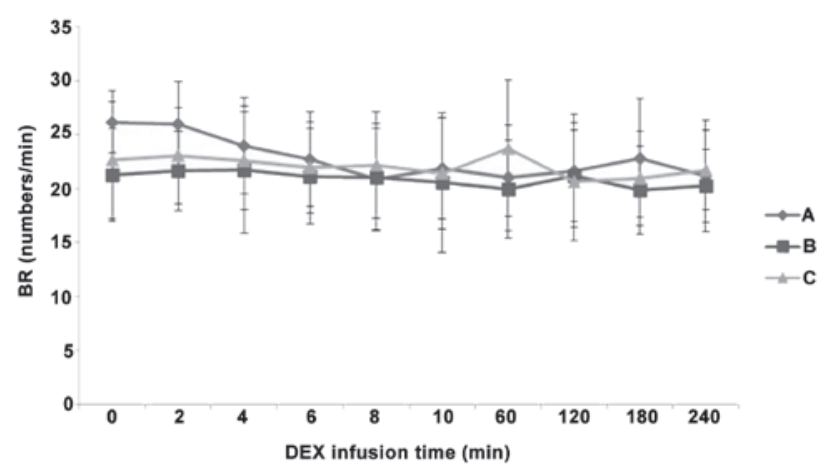

Figure 6. BR values in the three groups at various time-points after IV pump infusion of DEX. Group A, $1.0 \mu \mathrm{g} / \mathrm{kg} / 10$ min DEX; group B, $0.5 \mu \mathrm{g} / \mathrm{kg} / 10 \mathrm{~min} \mathrm{DEX}$; and group C, $0.4 \mu \mathrm{g} / \mathrm{kg} / \mathrm{h}$ DEX; BR, breathing rate; DEX, dexmedetomidine.

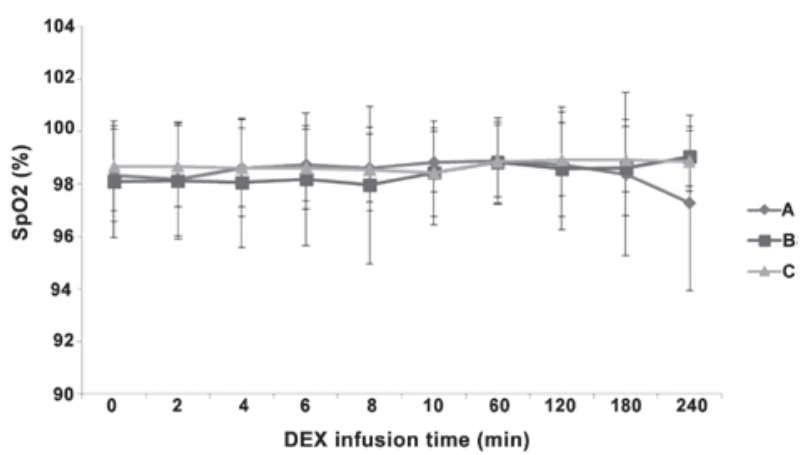

Figure 7. $\mathrm{SpO}_{2}$ values in the three groups at various time-points after IV pump infusion of DEX. Group A, $1.0 \mu \mathrm{g} / \mathrm{kg} / 10 \mathrm{~min}$ DEX; group B, $0.5 \mu \mathrm{g} / \mathrm{kg} / 10 \mathrm{~min} \mathrm{DEX}$; and group C, $0.4 \mu \mathrm{g} / \mathrm{kg} / \mathrm{h} \mathrm{DEX} ; \mathrm{SpO}_{2}$, peripheral capillary oxygen saturation; DEX, dexmedetomidine.

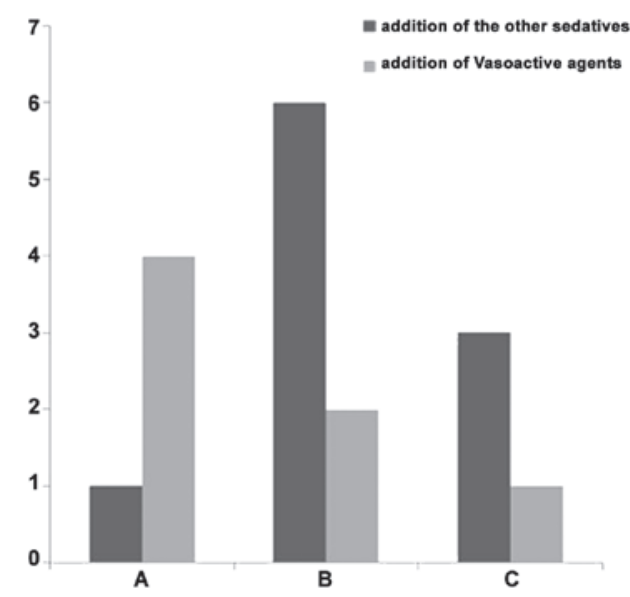

Figure 8. Concomitant use of medications in the three groups. Group A, $1.0 \mu \mathrm{g} / \mathrm{kg} / 10 \mathrm{~min}$ DEX; group B, $0.5 \mu \mathrm{g} / \mathrm{kg} / 10 \mathrm{~min}$ DEX; and group C, $0.4 \mu \mathrm{g} / \mathrm{kg} / \mathrm{h}$ DEX; DEX, dexmedetomidine.

60 min after IV pump infusion of DEX $(\mathrm{P}<0.05)$, while there was no significant difference in HR between groups $A$ and $B$ (P>0.05; Fig. 3). At 8 min after IV pump infusion of DEX, SBP decreased more evidently in group A compared with the value in group $\mathrm{C}(\mathrm{P}<0.05 ; \mathrm{Fig}$. 4). In addition, at $10 \mathrm{~min}$ after IV pump infusion, SBP decreased more evidently in group A compared with the value in both groups $\mathrm{B}$ and $\mathrm{C}(\mathrm{P}<0.05)$. 




However, no statistically significant differences were detected in SBP reduction among the three groups during the maintenance period $(\mathrm{P}>0.05)$. DBP was significantly decreased in group A compared with groups $\mathrm{B}$ and $\mathrm{C}$ at $8 \mathrm{~min}$ and $60 \mathrm{~min}$ after IV pump infusion ( $\mathrm{P}<0.05$; Fig. 5). DBP in group $\mathrm{B}$ was increased compared with groups $\mathrm{A}$ and $\mathrm{C}$ at 120 min after IV pump infusion $(\mathrm{P}<0.05)$, while it decreased more significantly in group A compared with group B at 240 min after IV pump infusion $(\mathrm{P}<0.05)$.

Differences in $\mathrm{BR}$ and $\mathrm{SpO}_{2}$ following IV pump infusion of DEX. There were no indications of respiratory arrest in any of the three groups, as well as no significant differences in $\mathrm{BR}$ and $\mathrm{SpO}_{2}$ values between the three groups $(\mathrm{P}>0.05)$. In addition, $\mathrm{SpO}_{2}$ was $>97 \%$ at all time points in all three groups (Figs. 6 and 7), indicating no indirect inhibition of respiration.

Concomitant use of medications. There was no significant difference between the three groups following addition of other sedatives $(\mathrm{P}>0.05)$. Vasoactive agents were administered to 4 patients in group A, 2 patients in group B and 1 patient in group $\mathrm{C}$, and the difference was not statistically significant (P>0.05; Table I; Fig. 8).

Drug withdrawal. DEX administration was suspended in 4 patients in group A, 4 patients in group B and no patients in group C. Drug withdrawal in group A was due to HR reduction of $>30 \%$ in 2 patients and an SBP value of $<90 \mathrm{mmHg}$ in the other 2 patients. Drug suspension in the 4 patients of group B was due to HR reduction of $>30 \%$ in 1 patient and an SBP value of $<90 \mathrm{mmHg}$ in the other 3 patients. HR and $\mathrm{BP}$ values gradually returned to the normal ranges following drug discontinuation, with no severe consequences in any of the 8 patients (Table II).

\section{Discussion}

Critically ill patients in ICUs frequently require various supportive therapies, including mechanical ventilation, vital sign monitoring, critical nursing care and constant illumination to maintain the patients in a long-term sleep-deprived state $(17,18)$. Therefore, appropriate sedative treatment is often required for ICU patients, as well as for postoperative patients and patients with severe multiple injuries. Midazolam, propofol and DEX are among the primary sedatives used in ICUs. DEX is a highly selective $\alpha_{2}$-adrenoceptor agonist that exerts its sedative and anti-anxiety effects by agonizing the brainstem locus ceruleus, which is the most concentrated area of $\alpha_{2}$ receptor in the central nervous system (19-21). DEX exerts an analgesic effect and ameliorates stress response; however, DEX simultaneously inhibits respiration by acting on $\alpha_{2}$ receptors in the presynaptic membrane of the spinal dorsal horn and postsynaptic membrane of interneurons $(22,23)$. DEX may be the preferred option for inducing sedation in ICU patients as it is able to reduce the occurrence of delirium and minimize the period of mechanical ventilation required $(24,25)$.

The results of the present study showed that continuous IV pump infusion of DEX was able to induce an ideal state of sedation (Ramsay score, 3-4) in all three groups of patients. The target level of sedation was achieved at $\sim 6 \mathrm{~min}$ 
after DEX infusion in groups A $(1.0 \mu \mathrm{g} / \mathrm{kg} / 10 \mathrm{~min})$ and B $(0.5 \mu \mathrm{g} / \mathrm{kg} / 10 \mathrm{~min})$. This is particularly crucial for the sedation of ICU patients, as antagonism between spontaneous breathing and mechanical ventilation may occur in patients if adequate sedation cannot be achieved rapidly, which may affect the target tidal volume, or even aggravate the existing pulmonary injury. Therefore, a key aim of using DEX is to enable the patient to enter an ideal state of sedation $(24,26)$. In addition, continuous IV pump infusion of DEX is able to maintain a Ramsay score of 3-4, at which the patient is in an arousable 'dormant' state, which may attenuate the injury from severe pathological factors while allowing the patient to be awakened if necessary in order to perform actions for the convenience of observing the condition and assessing neurological functions.

A previous study demonstrated that DEX has the function of bidirectional regulation of the cardiovascular system (27). DEX initially agonizes the $\alpha_{2 \mathrm{~B}}$ receptor of the postsynaptic membrane of the vascular smooth muscle to induce tachycardia and hypertension via vascular constriction. Subsequently, hypotension is induced via vascular dilation under the central sympatholytic effect produced by the continuous infusion of DEX. Therefore, DEX exerts a predictable effect on hemodynamics (28). In the present patients, HR, SBP and DBP tended to decrease following IV pump infusion with DEX; however, all the mean values of these parameters were within the normal ranges at all time points (HR, >60 bpm; SBP, >115 $\mathrm{mmHg}$; and SBP, >60 mmHg). DEX administration was suspended in 8 patients in the present study due to unstable hemodynamics. The HR and BP values of these patients were restored gradually to within normal ranges following the withdrawal of DEX, with no severe consequences.

Analysis of 8 patients (4 with hypercapnia, 3 with anemia and 1 with hypercapnia and anemia) who were withdrawn from DEX indicates that hypercapnia and anemia are two high-risk factors contributing to unstable hemodynamics. The primary causes underlying these results may be explained as follows: i) Patients with acute exacerbation of chronic obstructive pulmonary disease (AECOPD) are the primary group of patients in ICUs that typically require mechanical ventilation due to unconsciousness and severe hypercapnia. A previous study demonstrated that COPD may excite the sympathetic nerve system and induce the reflectory release of norepinephrine from the heart, causing hypertension and increasing the HR (29). In COPD patients with hypercapnia, the sympathetic system may be in a state of persistent excitement even under normal blood gas conditions $(30,31)$. ii) Peripheral vascular dilation, decline in BP, excitement of the sympathetic system, increase in HR and cardiac output and subsequent renal vascular restriction, water-sodium retention and increased $\mathrm{BP}$ are the primary physiopathological changes observed in anemic patients. iii) The $\alpha_{2 A}$ receptor subtype serves a crucial role in the pharmacology of DEX. This receptor exists in pre- and postsynapses, primarily serving the function of inhibiting norepinephrine release and neural excitement. DEX inhibits norepinephrine release by agonizing the presynaptic membrane $\alpha_{2}$ receptor, thus terminating transmission of the pain signal. In addition, DEX inhibits the sympathetic activity by agonizing the postsynaptic membrane $\alpha_{2}$ receptor. When the in vivo blood concentration of DEX is sufficient to inhibit sympathetic activity, the effect of sympathetic excitement induced by AECOPD and anemia is also inhibited. This mechanism may underlie the observed reduction in cardiovascular function and the more marked differences in HR and BP in patients with AECOPD and anemia (32-34). This mechanism is consistent with the results of the present study, which identified that the majority of patients that were withdrawn from DEX suffered from hypercapnia and anemia.

An ideal state of sedation may be achieved using the maintenance dose of DEX $(0.4 \mu \mathrm{g} / \mathrm{kg} / \mathrm{h})$; however, this effect is induced slowly. In order to achieve a more rapid sedative effect, we suggest the use of a loading dose of $0.5 \mu \mathrm{g} / \mathrm{kg} / 10 \mathrm{~min}$. In patients with AECOPD and anemia, high loading doses at a rapid rate of IV pump infusion should be avoided. Combination medication may be considered if necessary. As the sample size of the present study is relatively small, the results obtained may not fully reflect the effect of DEX on the circulatory system. Multi-center randomized controlled trials in larger samples are required to verify the present conclusions.

\section{References}

1. Oldham M and Pisani MA: Sedation in critically ill patients. Crit Care Clin 31: 563-87, 2015.

2. Genta PR, Eckert DJ, Gregorio MG, Danzi NJ, Moriya HT, Malhotra A and Lorenzi-Filho G: Critical closing pressure during midazolam-induced sleep. J Appl Physiol (1985) 111: 1315-1322, 2011.

3. Perrier ND, Baerga-Varela Y and Murray MJ: Death related to propofol use in an adult patient. Crit Care Med 28: 3071-3074, 2000.

4. Pichot C, Ghignone M and Quintin L: Dexmedetomidine and clonidine: From second- to first-line sedative agents in the critical care setting? J Intensive Care Med 27: 219-237, 2012.

5. Rayner SG, Weinert CR, Peng H, Jepsen S and Broccard AF; Study Institution: Dexmedetomidine as adjunct treatment for severe alcohol withdrawal in the ICU. Ann Intensive Care 23: $12,2012$.

6. Yang L, Xu JM, Jiang X, Ruan W, Cui Y and He L: Effect of dexmedetomidine on plasma brain-derived neurotrophic factor: A double-blind, randomized and placebo-controlled study. Ups J Med Sci 118: 235-239, 2013.

7. Chrysostomou C1, Beerman L, Shiderly D, Berry D, Morell VO and Munoz R: Dexmedetomidine: A novel drug for the treatment of atrial and junctional tachyarrhythmias during the perioperative period for congenital cardiac surgery: A preliminary study. Anesth Analg 107: 1514-1522, 2008.

8. Jalowiecki P, Rudner R, Gonciarz M, Kawecki P, Petelenz M and Dziurdzik P: Sole use of dexmedetomidine has limited utility for conscious sedation during outpatient colonoscopy. Anesthesiology 103: 269-273, 2005.

9. Giovannitti JA Jr, Thoms SM and Crawford JJ: Alpha-2 adrenergic receptor agonists: A review of current clinical applications. Anesth Prog 62: 31-39, 2015.

10. Longrois D, Conti G, Mantz J, Faltlhauser A, Aantaa R and Tonner P: Sedation in non-invasive ventilation: Do we know what to do (and why)? Multidiscip Respir Med 9: 56, 2014.

11. Nishizawa T, Suzuki H, Sagara S, Kanai T and Yahagi N: Dexmedetomidine versus midazolam for gastrointestinal endoscopy: A meta-analysis. Dig Endosc 27: 8-15, 2015.

12. Goodwin HE, Gill RS, Murakami PN, Thompson CB, Lewin JJ 3rd and Mirski MA: Dexmedetomidine preserves attention/calculation when used for cooperative and short-term intensive care unit sedation. J Crit Care 28: 1113.e7-1113.e10, 2013.

13. Ludtke KA, Stanley KS, Yount NL and Gerkin RD: Retrospective review of critically ill patients experiencing alcohol withdrawal: Dexmedetomidine versus propofol and/or lorazepam continuous infusions. Hosp Pharm 50: 208-213, 2015.

14. Bhana N, Goa KL and McClellan KJ: Dexmedetomidine. Drugs 59: 263-270, 2000.

15. Bassett R, Adams KM, Danesh V, Groat PM, Haugen A, Kiewel A, Small C, Van-Leuven M, Venus S and Ely EW: Rethinking critical care: Decreasing sedation, increasing delirium monitoring, and increasing patient mobility. Jt Comm J Qual Patient Saf 41: 62-74, 2015. 
16. Del Bufalo C, Morelli A, Bassein L, Fasano L, Quarta CC, Pacilli $\mathrm{AM}$ and Gunella G: Severity scores in respiratory intensive care: APACHE II predicted mortality better than SAPS II. Respir Care 40: 1042-1047, 1995.

17. Maraboto E: ABCDEs of ICU: Choice of sedative. Crit Care Nurs Q 36: 157-162, 2013.

18. Devabhakthuni S, Armahizer MJ, Dasta JF and Kane-Gill SL: Analgosedation: A paradigm shift in intensive care unit sedation practice. Ann Pharmacother $46: 530-540,2012$.

19. Gudmundsson G, Ulrik CS, Gislason T, Lindberg E, Brøndum E, Bakke $\mathrm{P}$ and Janson C: Long-term survival in patients hospitalized for chronic obstructive pulmonary disease: A prospective observational study in the Nordic countries. Int J Chron Obstruct Pulmon Dis 7: 571-576, 2012.

20. Ai-Ping C, Lee KH and Lim TK: In-hospital and 5-year mortality of patients treated in the ICU for acute exacerbation of COPD: A retrospective study. Chest 128: 518-524, 2005.

21. Andreas S, Haarmann H, Klarner S, Hasenfuss G and Raupach T: Increased sympathetic nerve activity in COPD is associated with morbidity and mortality. Lung 192: 235-241, 2014.

22. Gerlach AT and Dasta JF: Dexmedetomidine: An updated review. Ann Pharmacother 41: 245-252, 2007.

23. Riker RR, Shehabi Y, Bokesch PM, Ceraso D, Wisemandle W, Koura F, Whitten P, Margolis BD, Byrne DW, Ely EW and Rocha MG; SEDCOM (Safety and Efficacy of Dexmedetomidine Compared With Midazolam) Study Group: Dexmedetomidine vs midazolam for sedation of critically ill patients: A randomized trial. JAMA 301: 489-499, 2009.

24. Pandharipande PP, Pun BT, Herr DL, Maze M, Girard TD, Miller RR, Shintani AK, Thompson JL, Jackson JC, Deppen SA, et al: Effect of sedation with dexmedetomidine vs lorazepam on acute brain dysfunction in mechanically ventilated patients: The MENDS randomized controlled trial. JAMA 298: 2644-2653, 2007.
25. Maldonado JR, Wysong A, van der Starre PJ, Block T, Miller C and Reitz BA: Dexmedetomidine and the reduction of postoperative delirium after cardiac surgery. Psychosomatics 50: 206-217, 2009.

26. Ozaki M, Takeda J, Tanaka K, Shiokawa Y, Nishi S, Matsuda K, Doi M, Kakihana Y, Fujino Y, Takinami M and Kawai M: Safety and efficacy of dexmedetomidine for long-term sedation in critically ill patients. J Anesth 28: 38-50, 2014.

27. Takata K, Adachi YU, Suzuki K, Obata Y, Sato S and Nishiwaki K: Dexmedetomidine-induced atrioventricular block followed by cardiac arrest during atrial pacing: A case report and review of the literature. J Anesth 28: 116-120, 2014.

28. Bharati S, Pal A, Biswas C and Biswas R: Incidence of cardiac arrest increases with the indiscriminate use of dexmedetomidine: A case series and review of published case reports. Acta Anaesthesiol Taiwan 49: 165-167, 2011.

29. Sakamaki F, Satoh T, Nagaya N, Kyotani S, Nakanishi N and Ishida Y: Abnormality of left ventricular sympathetic nervous function assessed by (123) I-metaiodobenzylguanidine imaging in patients with COPD. Chest 116: 1575-1581, 1999.

30. Victor RG and Shafiq MM: Sympathetic neural mechanisms in human hypertension. Curr Hypertens Rep 10: 241-247, 2008.

31. Brown SJ, Raman A, Barnes MJ and Mundel T: Autonomic cardiovascular response to acute hypoxia and passive head-up tilting in humans. Eur J Appl Physiol 113: 1731-1736, 2013.

32. Vincent JL, Baron JF, Reinhart K, Gattinoni L, Thijs L, Webb A, Meier-Hellmann A, Nollet G, Peres-Bota D; ABC (Anemia and Blood Transfusion in Critical Care) Investigators: Anemia and blood transfusion in critically ill patients. JAMA 288: 1499-1507, 2002.

33. Dünser MW and Hasibeder WR: Sympathetic overstimulation during critical illness: Adverse effects of adrenergic stress. J Intensive Care Med 24: 293-316, 2009.

34. Franchitto N, Despas F, Labrunée M, Roncalli J, Boveda S, Galinier M, Senard JM and Pathak A: Tonic chemoreflex activation contributes to increased sympathetic nerve activity in heart failure-related anemia. Hypertension 55: 1012-1017, 2010. 